\title{
Decolorization of Reactive Dyes from Aqueous Solution Using Combined Coagulation-Flocculation and Photochemical Oxidation $\left(\mathrm{UV} / \mathrm{H}_{2} \mathrm{O}_{2}\right)$
}

\author{
M Z Bin Mukhlish ${ }^{1}$, M R Khan ${ }^{2 *}$, M S Islam ${ }^{3}$, M I Nazir ${ }^{1}$, J S Snigdha ${ }^{1}$, R Akter $^{1}$, H Ahmad ${ }^{1}$ \\ ${ }^{1}$ Department of Chemical Engineering and Polymer Science, Shahjalal University of Science and Technology, Sylhet 3114, Bangladesh \\ ${ }^{2}$ Department of Chemical Engineering, College of Engineering, Universiti Malaysia Pahang, 26300 Gambang, Pahang, Malaysia \\ ${ }^{3}$ Department of Animal Husbandry and Veterinary Science, University of Rajshahi, Rajshahi-6205, Bangladesh \\ E-mail: mrkhancep@yahoo.com,mrkhan@ump.edu.my
}

\begin{abstract}
Removal of reactive dyes from wastewater is a great environmental concern. Attempts were made to study the performance of a coupling process of coagulation-flocculation (CF) and photochemical oxidation (PCO) for the removal of two reactive dyes (Reactive Black 5 (RB 5) and Reactive Orange 12 (RO 12)) from aqueous solution. The CF experiments were conducted using alum as coagulant and polyacrylamide as coagulant aid whereas the PCO tests were carried out using $\mathrm{H}_{2} \mathrm{O}_{2}$ in the presence of UV light irradiation. Effects of various process parameters such as $\mathrm{pH}$, coagulant dose and coagulant aid dose on the CF process, and $\mathrm{H}_{2} \mathrm{O}_{2}$ dose and UV exposure time on the PCO method have been studied. The study reveals that only the CF process is not sufficient to treat the dye solution. The CF step could remove $52.30 \%$ and $41.38 \%$ of RB 5 and RO 12, respectively. At the best conditions of process parameters, the combined CF-PCO method results in color removals of $87.10 \%$ and $82.53 \%$ for RB 5 and RO 12, respectively. The combined process of CF and UV/ $\mathrm{H}_{2} \mathrm{O}_{2}$ may be a useful treatment technique for wastewater contaminated with reactive dyes.
\end{abstract}

Keywords: reactive dye, combined process, coagulation-flocculation, $\mathrm{UV} / \mathrm{H}_{2} \mathrm{O}_{2}$

\section{Introduction}

Dyes are widely used in textile industries to color their products. The textile industries consume a large volume of water and produce a huge amount of wastewater during all phases of textile production and finishing ${ }^{[1]}$. The dye effluents generated from these industries may pose a serious problem to the environment as most dyes are synthetic compounds with complex aromatic molecular structures, which make them resistant to light, heat and oxidizing agents, non-biodegradable, and toxic to life with carcinogenic and mutagenic effects ${ }^{[2-5]}$.

Among different types of dyes used in textile industries, $60-70 \%$ are azo compounds. Reactive dyes, one of the prominent and most widely used types of azo dyes, are characterized by a fiber-reactive component bonded to an appropriate azo, anthraquinone, phthalocyanine or metal complex dye ${ }^{[6]}$. These dyes are highly soluble in water and also have low levels of fixing to fibers. About $50 \%$ of the reactive dyes are lost through hydrolysis during the dyeing process and a large quantity of the dyes appears in wastewater. Moreover, these dyes are considered to be the most problematic compared to other forms of dyes, as they tend to pass through conventional treatment systems unaffected ${ }^{[7-9]}$. Consequently, the treatment of wastewater containing reactive dyes is a practical environmental challenge, and there is a constant need to develop an effective method that can efficiently remove these ecotoxic dyes.

Many attempts have been made for the removal of reactive dyes in wastewater using conventional treatment methods such as biological treatment ${ }^{[10]}$, adsorption ${ }^{[11,12]}$, membrane filtration ${ }^{[13]}$, chemical coagulation ${ }^{[14]}$ and advanced oxidation. Despite several advantages, there are some disadvantages and limitations for various dye treatment methods, and up to now there is no single and cost-effectively attractive method that can efficiently decolorize the dye effluent ${ }^{[1,15,16]}$. Through the biological treatment method, the removal of reactive dyes is difficult due to low biodegradability and/or low level of absorption of the dye onto activated sludge during treatment. The other limitations of this method are the longer duration of treatment, toxicity of dyes, large operational area, post-treatment of sludge, and requirement of specific bioreactors ${ }^{[17]}$. The color removal through the adsorption method is based on the affinity of dyes towards the adsorbents. Various adsorbents such as activated carbon ${ }^{[18]}$, carbon microspheres ${ }^{[19]}$, sulfur-doped carbon sphere ${ }^{[20]}, \mathrm{Fe}_{3} \mathrm{O}_{4} @ \mathrm{SiO}_{2} @ \mathrm{NH}_{2}$

Copyright (C)2020 M R Khan et al.

DOI: https://doi.org/10.37256/sce.122020214.51-61

This is an open-access article distributed under a CC BY license

(Creative Commons Attribution 4.0 International License)

https://creativecommons.org/licenses/by/4.0/ 
nanocomposite ${ }^{[21]}$, sawdust ${ }^{[22]}$, Pará chestnut husk ${ }^{[23]}$, zeolite ${ }^{[24]}$, Silica ${ }^{[25]}$, and alginate-montmorillonite-polyaniline ${ }^{[26]}$ have been studied for the adsorption of dyes and other organic pollutants from wastewater. However, the most commonly used adsorbent is activated carbon but it is expensive and neither the regeneration nor the disposal of used adsorbent is straightforward ${ }^{[27,28]}$. Polymeric membranes or nanoparticles/polymer composite membranes have been used for the removal of dyes from colored wastewater ${ }^{[13,29-32]}$. The basic problem involved in any membrane-based process is the decline in flux and the fouling of the membrane surface ${ }^{[6]}$. The coagulation-flocculation $(\mathrm{CF})$ method for dye removal usually consists of destabilization of the colloids by coagulation-flocculation followed by phase separation of dye-loaded sludge through sedimentation ${ }^{[33-35]}$. This method is relatively cheap ${ }^{[27,36]}$ and effectively decolorizes insoluble dyes (such as disperse dyes), but does not work well for soluble reactive dyes ${ }^{[37-39]}$. Chemical oxidation with ozone, and photochemical oxidation with a combination of UV radiation, ozone or $\mathrm{H}_{2} \mathrm{O}_{2}$ are promising methods based on the generation of reactive free hydroxyl radicals that react with organic pollutants to form carbon dioxide, water, and other oxidation products during the oxidative degradation. These methods are suitable to deal with highly toxic and low biodegradable wastes, but their costs are very high for effluent treatment ${ }^{[37,40]}$.

The combined treatment techniques can be applied in a complementary manner, in such a way as to compensate for deficiencies of the single processes when used independently. To reduce the load on the costly photochemical oxidation (PCO) method, CF can be used as a pretreatment step with subsequent PCO using UV/ $\mathrm{H}_{2} \mathrm{O}_{2}$. To overcome the disadvantages of individual processes, some other combined processes such as membrane bioreactor $\left(\mathrm{MBR}{ }^{[41]}\right.$, MBR coupled with reverse osmosis ${ }^{[42]}$, electrocoagulation coupled with adsorption ${ }^{[43]}$, ozonation coupled with electrocoagulation ${ }^{[4]}$, hydrodynamic cavitation or acoustic cavitation combined with chemical oxidation ${ }^{[45]}$, nanofiltration coupled with electrolytic oxidation ${ }^{[46]}$, CF followed by nanofiltration ${ }^{[6]}$, ultrasonication coupled with microbial removal ${ }^{[47]}$, $\mathrm{CF}$ combined with electrocoagulation ${ }^{[48]}$, CF coupled with adsorption ${ }^{[49]}$, and chemical oxidation followed by adsorption and microbial techniques ${ }^{[50]}$ have been studied over past few years. So far, there is only a little information on the combined treatment process of $\mathrm{CF}$ and $\mathrm{UV} / \mathrm{H}_{2} \mathrm{O}_{2}$ for the removal of reactive dyes.

The objective of the present work was to study the performance of the CF process in combination with the PCO (UV/ $\mathrm{H}_{2} \mathrm{O}_{2}$ ) method for the removal of reactive dyes from aqueous solution. Alum and polyacrylamide were used as coagulant and coagulant aid, respectively while hydrogen peroxide was used as the oxidant. The most effective operational conditions for CF and PCO methods were determined.

\section{Materials and methods}

\subsection{Materials}

The experiments were performed using two commercially available reactive dyes namely, Reactive Black 5 (RB 5) and Reactive Orange 12 (RO 12), collected from a local textile industry, Bangladesh. The structures, molecular weight and wavelength of maximum absorbance $\left(\lambda_{\max }\right)$ of the dyes are shown in Table 1. Polyacrylamide was obtained from Chemitec Properties Ltd., Bangladesh. Alum $\left[\mathrm{Al}_{2}\left(\mathrm{SO}_{4}\right)^{3} .18 \mathrm{H}_{2} \mathrm{O}\right]$, hydrochloric acid $(\mathrm{HCl})$, sodium hydroxide $(\mathrm{NaOH})$ and hydrogen peroxide $\left(\mathrm{H}_{2} \mathrm{O}_{2}\right)(30 \% \mathrm{w} / \mathrm{w})$ were purchased from MERCK, Germany.

Table 1. The general characteristics of RB 5 and RO $12^{[6,51,52]}$

Dye


Separate stock solutions of the two dyes were prepared by dissolving $1000 \mathrm{mg}$ of respective dye (RB 5 or RO 12) in $1 \mathrm{~L}$ distilled water. The experimental 'fresh dye solutions' were prepared by diluting stock solutions to the desired concentrations. The $\mathrm{pH}$ of $100 \mathrm{mg} / \mathrm{L}$ fresh dye (RB 5 or RO 12) solution was recorded as 5.5 . For adjusting the $\mathrm{pH}$ of dye solution to the required value, sodium hydroxide $(\mathrm{NaOH}) 0.1 \mathrm{M}$ or hydrochloric acid $(\mathrm{HCl}) 0.1 \mathrm{M}$ was used.

Dye concentration in aqueous solution was evaluated using a UV spectrophotometer (UV-1601, Shimadzu, Japan) at $\lambda_{\max }$ (i.e., $598 \mathrm{~nm}$ and $416 \mathrm{~nm}$ for RB 5 and RO 12, respectively). A pH meter (HI8014, HANNA Instruments, Singapore) was used for measuring the $\mathrm{pH}$ and a Jar Test apparatus was used to conduct the CF process. A UV lamp (100 watt) was used as the UV irradiation source.

\subsection{Coagulation-flocculation method}

To explore the best operational conditions of process parameters (dose of coagulant and coagulant aid, and $\mathrm{pH}$ ) for the CF method, experiments were conducted in a jar test apparatus containing six jars. Each jar was filled with $1 \mathrm{~L}$ of fresh dye solution (initial dye concentration, $\mathrm{Co}=100 \mathrm{mg} / \mathrm{L}$ ) and necessary doses of coagulant (alum) and coagulant aid (polyacrylamide) were added. Just after the addition of coagulant and coagulant aid, the solution was mixed rapidly (300 $\mathrm{rpm}$ ) for $3 \mathrm{~min}$ to disperse the chemicals followed by slow mixing $(60 \mathrm{rpm})$ for $30 \mathrm{~min}$ to aid floc formation. Then stirring was stopped and flocs were allowed to settle down for $70 \mathrm{~min}$. The remaining dye concentration (C) of the supernatant was measured at the end of the sedimentation period. The experimental conditions for the CF process were selected based on previous studies and primarily study. During the study of the influence of $\mathrm{pH}$ on the CF process, the initial dye solution was adjusted to the $\mathrm{pH}$ in the range of 2-9 before being subjected to the jar test. The dye removal efficiency was defined as $\mathrm{C} / \mathrm{Co}$, where $\mathrm{Co}$ was the initial concentration of dye, and $\mathrm{C}$ was the remaining concentration dye in the solution.

\subsection{Photochemical Oxidation ( $\left.\mathrm{UV} / \mathrm{H}_{2} \mathrm{O}_{2}\right)$ studies}

The residual dye solution concentrations were $47.70 \mathrm{mg} / \mathrm{L}(\mathrm{pH} 6.3$ ) and $58.62 \mathrm{mg} / \mathrm{L}(\mathrm{pH} 5.9)$ for $\mathrm{RB} 5$ and RO 12, respectively at the end of CF step conducted at the best operational conditions of process parameters (e.g., initial dye solution $\mathrm{pH}$, and doses of coagulant and coagulant aid). The effluent dye solution obtained from the CF process was the raw solution for the second step of the coupled process, i.e. $\mathrm{PCO}\left(\mathrm{UV} / \mathrm{H}_{2} \mathrm{O}_{2}\right)$. Figure 1 shows the outline of coupling of the CF process with the PCO step.

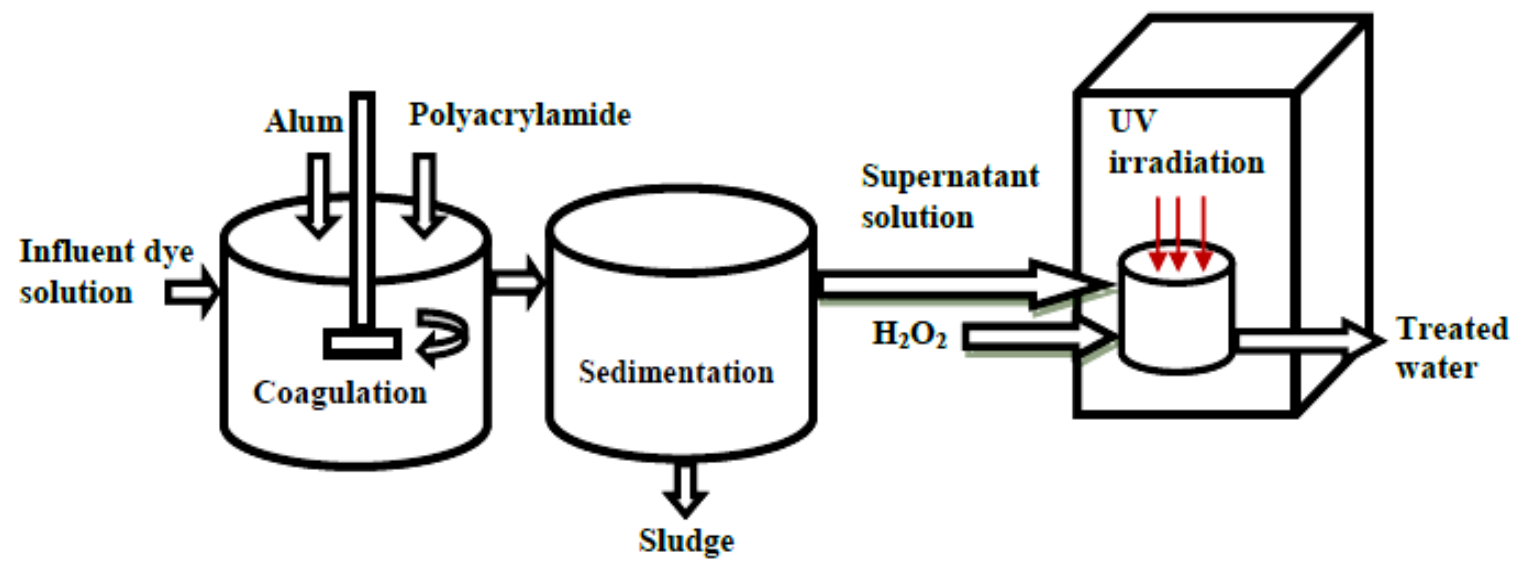

\section{Coagulation-flocculation}

Photochemical oxidation

Figure 1. Coupling of coagulation-flocculation and photochemical oxidation methods for the removal of reactive dyes

The PCO tests were performed in a batch photoreactor system. The reactor consists of a beaker placed in a rectangular box and a UV lamp (100 watt) was hanged at $10 \mathrm{~cm}$ apart on the overhead of the beaker. The penetration of UV light to the outside was prevented using a loose and removable reflective aluminum foil around the reactor.

In each experimental run, $250 \mathrm{~mL}$ of dye solution was taken into the beaker and a certain dose of $\mathrm{H}_{2} \mathrm{O}_{2}$ was added into the solution followed by UV lamp irradiation (at $254 \mathrm{~nm}$ ) from the top of the reactor. After a certain period, the remaining concentration $(\mathrm{C})$ of the dye solution was measured. To determine the most effective dose of $\mathrm{H}_{2} \mathrm{O}_{2}$ for color removal, the PCO process was first analyzed with different doses of $\mathrm{H}_{2} \mathrm{O}_{2}$ at a constant UV irradiation time of 60 min. Then the PCO tests were carried out at the best dose of $\mathrm{H}_{2} \mathrm{O}_{2}$ varying the UV irradiation time. In this case, $5 \mathrm{~mL}$ of the sample was withdrawn from the beaker at a regular time interval of $10 \mathrm{~min}$ and after analyzing the dye concentration, the solution was returned into the beaker. 
The overall system efficiency of the combined process was evaluated from the difference in dye concentration between the influent of the CF process and the effluent of the PCO process.

\section{Results and discussion}

\subsection{Coagulation-flocculation method for dye removal}

\subsubsection{Effect of dose of coagulant and coagulant aid on dye removal}

An insufficient dose or overdosing of coagulant and coagulant aid would result in poor performance in the CF process. It is crucial to determine the most favorable dose to minimize the dosing cost and obtain the best performance in the treatment.
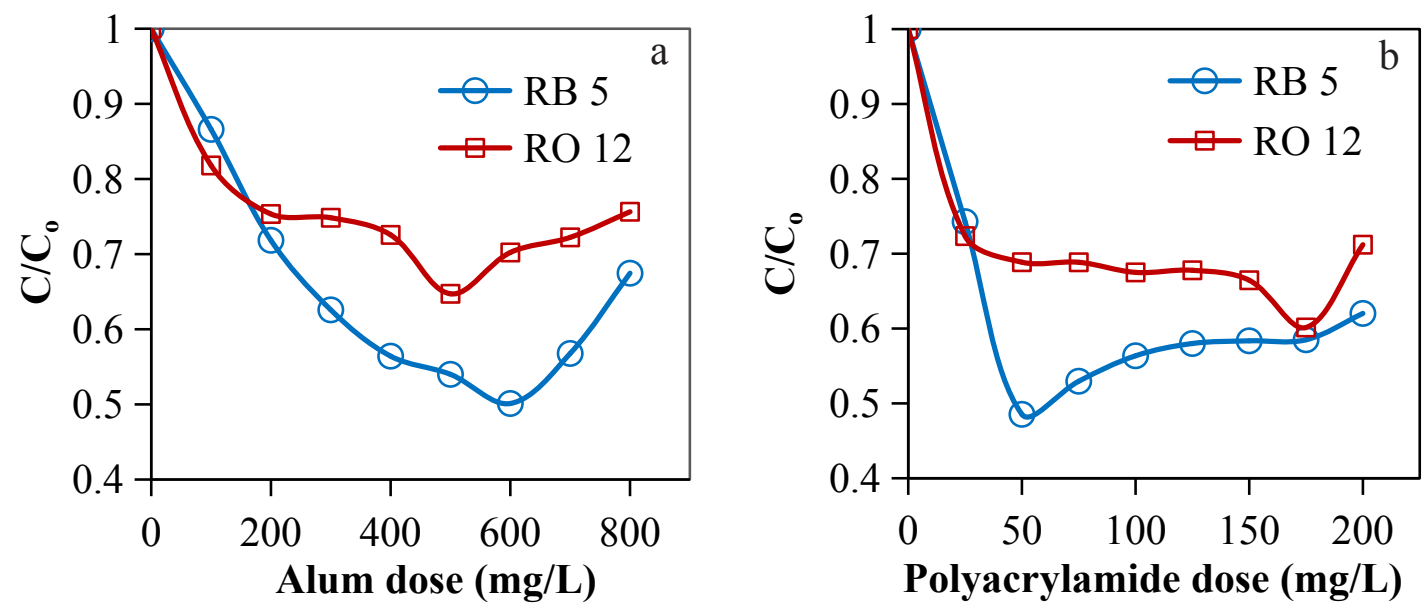

Figure 2. Effect of (a) alum dose (at polyacrylamide dose of $150 \mathrm{mg} / \mathrm{L}$ ) and (b) polyacrylamide dose (at alum doses of $600 \mathrm{mg} / \mathrm{L}$ and $500 \mathrm{mg} / \mathrm{L}$ for RB 5 and RO 12, respectively) on the removal of dyes in CF process

The CF tests were first conducted at $\mathrm{pH} 5.5$ (natural $\mathrm{pH}$ of dye solution), initial dye solution concentration (Co) of $100 \mathrm{mg} / \mathrm{L}$ and an arbitrary dose of coagulant aid $(150 \mathrm{mg} / \mathrm{L})$, varying the dose of coagulant from $100 \mathrm{mg} / \mathrm{L} \mathrm{to} 800 \mathrm{mg} / \mathrm{L}$. Figure 2 a shows the removal efficiencies of RB 5 and RO 12 as a function of coagulant (alum) concentration at a constant dose of polyacrylamide $(150 \mathrm{mg} / \mathrm{L})$. As shown in Figure $2 \mathrm{a}$, the dye removal performance increased up to a certain dose of coagulant and after that the performance decreased. At the fixed-dose of polyacrylamide $(150 \mathrm{mg} / \mathrm{L})$, the maximum dye removal of $49.88 \%$ and $35.28 \%$ were achieved respectively at the coagulant doses of $600 \mathrm{mg} / \mathrm{L}$ and $500 \mathrm{mg} / \mathrm{L}$ for $\mathrm{RB} 5$ and RO 12, respectively. The difference in maximum removal performance may also arise from the different molecular masses and chemical structures of two reactive dyes. As shown in Table 1, RB 5 has a higher molecular mass compared to RO 12. Moreover the RB 5 dye has four sulfonic acid groups whereas the RO 12 dye contains three of these groups. When alum is dissolved in water, the formation of cations occurs which combine with dye anions to form an insoluble complex. Consequently the dye removal using the CF process was more efficient for RB 5 which settles easier than RO 12.

To explore the most effective dose of coagulant aid for color removal, $\mathrm{CF}$ experiments were carried out at $\mathrm{pH} 5.5$, the initial dye concentration of $100 \mathrm{mg} / \mathrm{L}$, and the alum dose of $600 \mathrm{mg} / \mathrm{L}$ and $500 \mathrm{mg} / \mathrm{L}$ for RB 5 and RO 12, respectively, varying the dose of polyacrylamide from $25 \mathrm{mg} / \mathrm{L}$ to $200 \mathrm{mg} / \mathrm{L}$. The dye removal efficiency as a function of different doses of polyacrylamide is shown in Figure $2 b$. It was noticed from the findings that the removal of dyes increased for the coagulant aid dose up to a certain dose. As shown in Figure 2b, the most effective doses of coagulant aid for color removal were $50 \mathrm{mg} / \mathrm{L}$ and $175 \mathrm{mg} / \mathrm{L}$ for RB 5 and RO 12, respectively. One of the largest uses of polyacrylamide is to flocculate solids in a liquid. Trivalent metal salt like aluminum sulfate is bridged by the long polymer chains of polyacrylamide. This polymeric coagulant aid causes the formation of flocks more quickly and increases the rate of sedimentation by bridging and connecting the already-formed flocks. Further, with that network formed during sedimentation, this coagulant aid takes other tiny particles, which couldn't form flocks inside them and make them sediment along with themselves ${ }^{[53]}$.

To check the coagulation-flocculation behavior at the most effective dose of coagulant aid, new tests were carried out at the polyacrylamide doses of $50 \mathrm{mg} / \mathrm{L}$ and $175 \mathrm{mg} / \mathrm{L}$ for RB and RO 12, respectively. The dose of alum was varied from $100 \mathrm{mg} / \mathrm{L}$ to $1000 \mathrm{mg} / \mathrm{L}$ while the initial dye concentration and $\mathrm{pH}$ were kept constant at $100 \mathrm{mg} / \mathrm{L}$ and 5.5, respectively. 


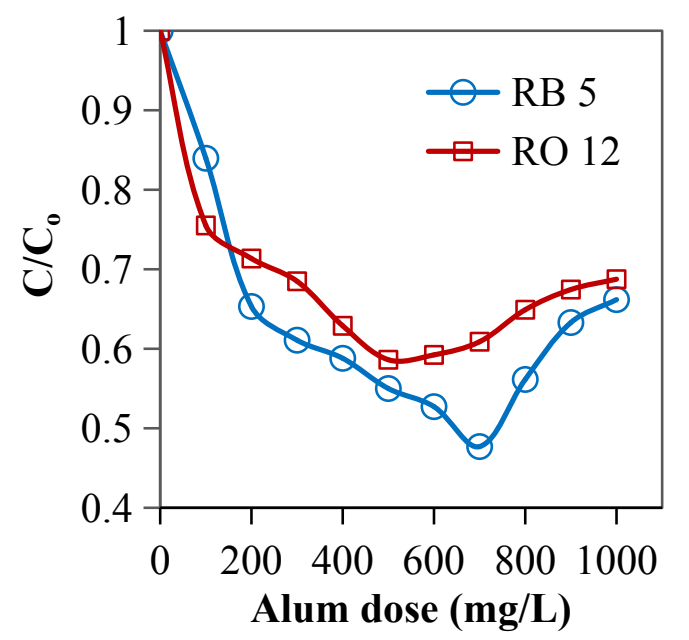

Figure 3. Effect of alum dose on the removal of dyes in the CF process at the most effective dose of polyacrylamide (50 mg/L for RB 5 and $175 \mathrm{mg} / \mathrm{L}$ for RO 12)

Figure 3 shows the removal of dyes as a function of coagulant concentration in the CF process carried out at the most effective dose of coagulant aid. It was found that removal of dye initially increased with the increase of alum dose up to a certain limit and then dye removal decreased with the application of higher doses of alum. The best performance in terms of color removal (52.30\% and $41.38 \%$ for RB 5 and RO 12, respectively) was achieved at the coagulant dose of $700 \mathrm{mg} / \mathrm{L}$ and $500 \mathrm{mg} / \mathrm{L}$ for RB 5 and RO 12, respectively. The remaining concentrations of RB 5 and RO 12 were $47.70 \mathrm{mg} / \mathrm{L}$ (final solution $\mathrm{pH} 6.3$ ) and $58.62 \mathrm{mg} / \mathrm{L}$ (final solution $\mathrm{pH} 5.9$ ), respectively. Daud et al. ${ }^{[54]}$ reported that waste removal increased with an increase in coagulant dose until it reached an optimum value, then the removal started to decrease. This could be attributed to the restabilization of colloidal particulates when coagulants were used at doses above the optimum value.

\subsubsection{Effect $\mathrm{pH}$ on dye removal in the coagulation-flocculation process}

Figure 4 shows the effect of initial dye solution $\mathrm{pH}$ (2 to 9) on the dye removal in the CF process. The conditions used were: initial dye concentration of $100 \mathrm{mg} / \mathrm{L}$; dose of alum of $700 \mathrm{mg} / \mathrm{L}$ for RB 5 and $500 \mathrm{mg} / \mathrm{L}$ for RO 12 and dose of polyacrylamide of $50 \mathrm{mg} / \mathrm{L}$ for RB 5 and $175 \mathrm{mg} / \mathrm{L}$ for RO 12 . The $\mathrm{CF}$ process was strongly influenced by the $\mathrm{pH}$ of initial dye solution. For both dyes, the best performance was achieved at the natural $\mathrm{pH}(5.5)$ of dye solution and the dye removals at this $\mathrm{pH}$ were $52.30 \%$ and $41.38 \%$ for $\mathrm{RB} 5$ and $\mathrm{RO} 12$, respectively. When alum is added to the aqueous solution, there is an interrelation between $\mathrm{pH}$ and the type of aluminum hydroxide formed. This in turn determines the charge on the hydrous oxide complex. At $\mathrm{pH} 5.5$, positively charged $\mathrm{Al}(\mathrm{OH})^{2+}$ and $\mathrm{Al}(\mathrm{OH})^{2+}$, and insoluble $\mathrm{Al}(\mathrm{OH})_{3}$ species prevailed. The dye removal could be explained by the fact that at the optimum $\mathrm{pH}$, dye particles retain net negative charges which enhance the performance of cationic coagulant. The anionic charges on RB 5 and RO 12 dyes in aqueous solution are neutralized by positively charged species of aluminum while insoluble aluminum species favor coagulation by sweep precipitation ${ }^{[49]}$. Apart from a narrow $\mathrm{pH}$ region approximately 5-6, the dominant soluble species are $\mathrm{Al}{ }^{3+}$ and $\mathrm{Al}(\mathrm{OH})^{4-}$ at low and high $\mathrm{pH}$, respectively ${ }^{[55]}$. It is also observed from Figure 4 that decolorization is very poor at low and high $\mathrm{pH}$ where soluble species of aluminum ions become predominant ${ }^{[48]}$. 


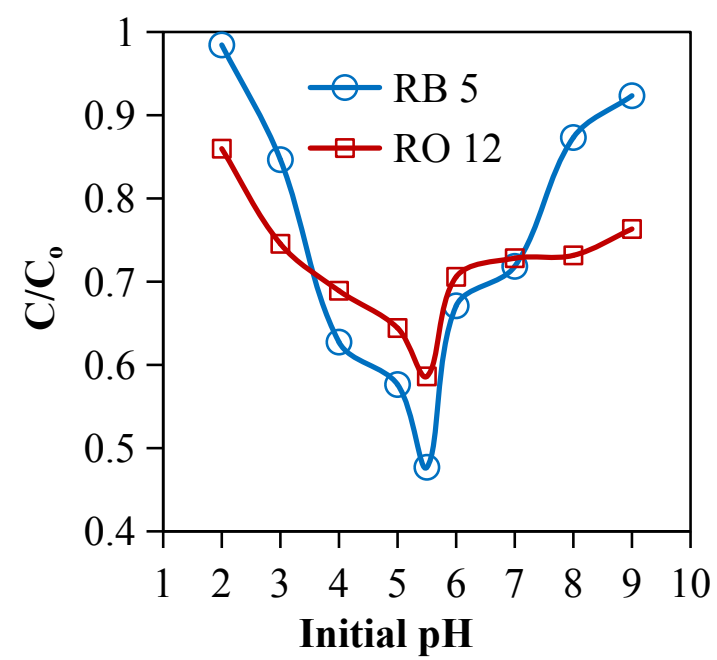

Figure 4. Effect of initial dye solution $\mathrm{pH}$ on the removal of dyes in the $\mathrm{CF}$ process

The best operational conditions of different parameters (coagulant dose, coagulant aid dose and $\mathrm{pH}$ ) for the $\mathrm{CF}$ process and the corresponding dye removal percentages were presented in Table 2. As shown in Table 2, the maximum percentage removals by the CF method were $52.30 \%$ and $41.38 \%$ for the dyes RB 5 and RO 12, respectively.

\begin{tabular}{ccccc}
\multicolumn{4}{c}{ Table 2. The best conditions for coagulation-flocculation process and the corresponding dye removal performance } \\
\hline Dye & Alum dose $(\mathrm{mg} / \mathrm{L})$ & Polyacrylamide dose $(\mathrm{mg} / \mathrm{L})$ & Polyacrylamide dose $(\mathrm{mg} / \mathrm{L})$ & Removal $(\%)$ \\
\hline RB 5 & 700 & 50 & 5.5 & 52.30 \\
RO 12 & 500 & 175 & 5.5 & 41.38 \\
\hline
\end{tabular}

Selcuk ${ }^{[56]}$ reported $60 \%$ color removal from real textile water at $1500 \mathrm{mg} / \mathrm{L}$ and $5 \mathrm{mg} / \mathrm{L}$ aluminum sulfate and anionic polyelectrolyte, respectively. About $48 \%$ removal of trihalomethane was achieved at the alum coagulant dose of $100 \mathrm{mg} / \mathrm{L}$ ${ }^{[57]}$. Wong et al. ${ }^{[58]}$ achieved $78 \%$ decolorization of CibacronYellow FN-2R reactive dye solution $(\mathrm{Co}=1000 \mathrm{mg} / \mathrm{L})$ at the alum dose of $6000 \mathrm{mg} / \mathrm{L}$. Mohamed et al. ${ }^{[59]}$ reported $49 \%$ color removal from mixed reactive dye solution $(\mathrm{Co}=12424$, $\mathrm{pH}=5$ ) at the alum dose of $3000 \mathrm{mg} / \mathrm{L}$. About $23 \%$ removal of color from real textile water was obtained at the alum dose of $400 \mathrm{mg} / \mathrm{L}^{[60]}$. Kim et al. ${ }^{[38]}$ reported that the maximum dye removal percentages for reactive blue 49 and reactive yellow 84 dyes were $60.9 \%$ and $71.3 \%$, respectively, at coagulant concentrations of 2.78 and $1.85 \mathrm{mM}$ ferric chloride.

\subsection{Photochemical Oxidation (PCO) of dyes using $\mathrm{H}_{2} \mathrm{O}_{2}$ and UV irradiation}

In this case, the CF step was first carried out at the best conditions of process parameters and the conditions used were: initial dye concentration of $100 \mathrm{mg} / \mathrm{L}$; initial dye solution $\mathrm{pH}$ value of 5.5 ; dose of alum of 700 and $500 \mathrm{mg} / \mathrm{L}$ for RB 5 and RO 12, respectively; and dose of polyacrylamide of 50 and $175 \mathrm{mg} / \mathrm{L}$ for RB 5 and RO 12, respectively. The residual dye solutions (with concentrations of $47.70 \mathrm{mg} / \mathrm{L}(\mathrm{pH} 6.3$ ) for $\mathrm{RB} 5$ and $58.62 \mathrm{mg} / \mathrm{L}(\mathrm{pH} 5.9$ ) for RO 12) obtained from the CF processes were the raw solutions for the second step of the coupling process, i.e. PCO $\left(\mathrm{UV} / \mathrm{H}_{2} \mathrm{O}_{2}\right)$. The CF treated dye solutions were treated with different doses of $\mathrm{H}_{2} \mathrm{O}_{2}(20-124 \mathrm{~mL} / \mathrm{L})$ under $\mathrm{UV}$ irradiation for 60 minutes and the dye removal efficiency as a function of $\mathrm{H}_{2} \mathrm{O}_{2}$ dose was represented in Figure 5a. As shown in Figure 5a, the best doses of $\mathrm{H}_{2} \mathrm{O}_{2}$ for color removal were $60 \mathrm{~mL} / \mathrm{L}$ and $100 \mathrm{~mL} / \mathrm{L}$ for RB 5 and RO 12, respectively.

The PCO process using $\mathrm{UV} / \mathrm{H}_{2} \mathrm{O}_{2}$ is based on the generation of highly reactive oxidants, primarily hydroxyl radical $(\cdot \mathrm{OH})$. This radical is the second most powerful oxidizing agent (after fluorine) with a redox potential of $\mathrm{E}^{\circ}\left(\cdot \mathrm{OH} / \mathrm{H}_{2} \mathrm{O}\right)=$ $2.8 \mathrm{~V} / \mathrm{SHE}$ and can non-selectively react with most organics and inorganics via hydroxylation or dehydrogenation ${ }^{[61,62]}$. Hydrogen peroxide (oxidation potential $\sim 1.78 \mathrm{~V}$ ) alone is ineffective in the treatment of textile wastewater at both alkaline and acidic $\mathrm{pH}$. Under UV irradiation, hydroxyl radicals $(\cdot \mathrm{OH})$ are produced by the decomposition of $\mathrm{H}_{2} \mathrm{O}_{2}$ as shown in Eq. $(1)^{[63,64]}$.

$$
\mathrm{H}_{2} \mathrm{O}_{2}+\mathrm{hv} \rightarrow 2 \mathrm{HO}^{*}
$$

Hydrogen peroxide $\left(\mathrm{H}_{2} \mathrm{O}_{2}\right)$ itself acts as an effective hydroxyl radical $(\cdot \mathrm{OH})$ scavenger as shown in Eq. (2) and Eq. (3) ${ }^{[36,65]}$. 


$$
\begin{aligned}
& \mathrm{H}_{2} \mathrm{O}_{2}+\mathrm{HO}^{-} \rightarrow \mathrm{HO}_{2}^{\prime}+\mathrm{H}_{2} \mathrm{O} \\
& \mathrm{H}_{2} \mathrm{O}_{2}+\mathrm{HO}^{-} \rightarrow \mathrm{O}_{2}^{--}+\mathrm{H}^{+}+\mathrm{H}_{2} \mathrm{O}
\end{aligned}
$$

Although $\mathrm{HO}_{2} \bullet$ promotes radical chain reactions and it is an oxidant itself, its oxidation potential is much lower than that of hydroxyl radical $(\bullet \mathrm{OH})$. Further, it is also reported that light energy delivered to the target site promotes the photosensitizer to an electronically excited state from which a number of reactive oxygen species, including singlet oxygen, are generated via electron or energy transfer processes ${ }^{[66]}$. The generated oxidizing agents $\left(\bullet \mathrm{OH}_{1} \mathrm{HO}_{2} \bullet, \mathrm{O}_{2} \bullet-\ldots\right)$ oxidize the organic dye molecules leading to intermediate compounds. Finally, complete mineralization is achieved through the further breakdown of theses intermediates by the oxidizing agents ${ }^{[63]}$. Therefore, it is assumed that the cumulative generation of oxidizing species from photo-excited $\mathrm{H}_{2} \mathrm{O}_{2}$ during photochemical oxidation was the prime cause of decolorization of tested dye solutions. It is also apparent from Figure 5a that the removal of dye increased with the increase in the dose of $\mathrm{H}_{2} \mathrm{O}_{2}$ up to a certain value. This enhancement in color removal by the addition of $\mathrm{H}_{2} \mathrm{O}_{2}$ is due to enhance of hydroxyl radical formation. Hydrogen peroxide, at low doses, cannot generate enough hydroxyl radical and the treatment will be limited reasonably ${ }^{[67]}$. The addition of more $\mathrm{H}_{2} \mathrm{O}_{2}$ above the best amount reduced the dye removal performance. This may be because an increase of $\mathrm{H}_{2} \mathrm{O}_{2}$ dose beyond the best dose causes the formation of low active hydroxyl radicals $\left(\mathrm{HO}_{2} \bullet\right)$, and reduces the efficiency of the oxidation process ${ }^{[36]}$. This phenomenon was also reported in the literature and was referred to as a scavenging effect ${ }^{[63]}$.
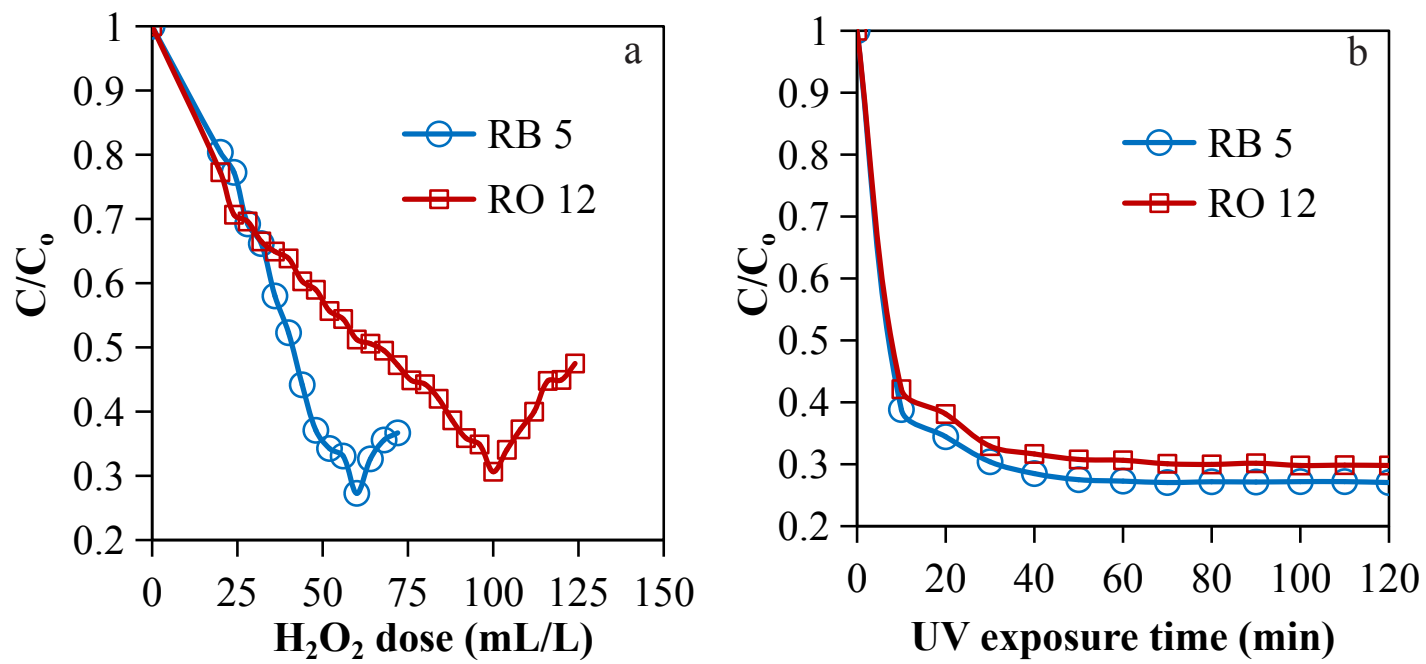

Figure 5. Effects of (a) dose of $\mathrm{H} 2 \mathrm{O} 2$ and (b) UV exposure time (10-120) on the removal of dyes in case of CF treated dye solution

Further, the effect of the UV exposure time (10-120 min) on dye removal was also checked at the best doses of $\mathrm{H}_{2} \mathrm{O}_{2}$ (i.e., $60 \mathrm{~mL} / \mathrm{L}$ and $100 \mathrm{~mL} / \mathrm{L}$ for RB 5 and RO 12, respectively) and the obtained result was presented in Figure $5 \mathrm{~b}$. It was found that there was no appreciable change in the dye removal performance after 60 min of UV irradiation. After 120 min of $\mathrm{UV} / \mathrm{H}_{2} \mathrm{O}_{2}$ treatment, the remaining dye solution concentrations were $12.9 \mathrm{mg} / \mathrm{L}$ and $17.47 \mathrm{mg} / \mathrm{L}$ for $\mathrm{RB} 5$ and $\mathrm{RO}$ 12 , respectively. The dye removal percentages by this step were found to be $72.95 \%$ and $70.19 \%$ for RB 5 and RO 12 , respectively. Mousavi et al. ${ }^{[68]}$ achieved 38\% removal of Rhodamine B dye $(\mathrm{Co}=100 \mathrm{mg} / \mathrm{L})$ by $\mathrm{UV} / \mathrm{H}_{2} \mathrm{O}_{2}$ method at the UV irradiation time of 80 minutes and $\mathrm{H}_{2} \mathrm{O}_{2}$ concentration of $100(\mathrm{mg} / \mathrm{L})$.

\section{Overall dye removal efficiency using combined $\mathrm{CF}$ and $\mathrm{PCO}\left(\mathrm{UV} / \mathrm{H}_{2} \mathrm{O}_{2}\right)$ methods}

The overall removal percentages achieved by the combined CF and PCO treatment system were $87.10 \%$ and $82.53 \%$ for RB 5 and RO 12, respectively. Almost similar results were observed from some other combined treatment techniques for reactive dye removal from water. Furlan et al. ${ }^{[69]}$ employed a combined treatment process consisting of $\mathrm{CF}$ and adsorption that allowed average color removals of $90 \%$ and $84 \%$, for the dyes RB 5 and reactive Orange 16, respectively. Riera-Torres et al. ${ }^{[6]}$ used the CF process in combination with the nanofiltration technique and observed that the combined process could remove $90 \%$ of RB 5 dye from aqueous solution. Harrelkas et al. ${ }^{[70]}$ studied CF coupled with membrane 
processes or adsorption for the treatment of reactive dye-containing wastewater and showed that the performances of $\mathrm{CF} /$ microfiltration, $\mathrm{CF} / \mathrm{ultrafiltration}$ and $\mathrm{CF} /$ adsorption combinations in terms of color removal were $65 \%, 74 \%$, and $50 \%$, respectively.

As reported by Yonar ${ }^{[36]}$, the $\mathrm{UV} / \mathrm{H}_{2} \mathrm{O}_{2}$ method is less expensive compared to some other advanced oxidation methods (such as $\mathrm{UV} / \mathrm{O}_{3}, \mathrm{UV} / \mathrm{O}_{3} / \mathrm{H}_{2} \mathrm{O}_{2}$, and ozonation), but is $\sim 18-22$ fold costlier than coagulation process. Despite the fact that the CF process is cheap, as observed in the present study this technique can remove only $52.30 \%$ and $41.38 \%$ of RB 5 and RO 12, respectively. On the other hand, the $\mathrm{UV} / \mathrm{H}_{2} \mathrm{O}_{2}$ method uses expensive reagent $\left(\mathrm{H}_{2} \mathrm{O}_{2}\right)$ and consumes large amounts of electrical energy (UV). As the CF process is much cheaper and can remove a significant percentage of dye, the pretreatment of dye solution with this technique will reduce the consumption of costly reagent and electricity in the subsequent $\mathrm{UV} / \mathrm{H}_{2} \mathrm{O}_{2}$ step. Therefore the combination of $\mathrm{CF}$ and $\mathrm{UV} / \mathrm{H}_{2} \mathrm{O}_{2}$ methods could be economically/energetically a more viable choice for the treatment of reactive dye-containing wastewater.

\section{Conclusions}

In this study, the performance of $\mathrm{CF}$ and $\mathrm{PCO}\left(\mathrm{UV} / \mathrm{H}_{2} \mathrm{O}_{2}\right)$ processes in terms of color removal from reactive dyecontaining wastewater was investigated. Our experiments showed that decolorization efficiency was affected by the process parameters such as dye solution $\mathrm{pH}$, coagulant and coagulant aid dose, hydrogen peroxide dose and UV exposure time. The best conditions of these parameters will contribute to minimizing the reactor size, reagent consumption and the costs associated with the treatment. The color removal percentage was different for the two dyes both in CF and PCO processes. We could not obtain complete color removal by a single process. The coupling of CF and PCO methods was more effective than the individual process. The best conditions for the combined treatment method yielded color removals of $87.10 \%$ and $82.53 \%$, for the dyes RB 5 and RO 12, respectively. According to our observations, this combined process can be applied for the treatment of reactive dye-containing wastewater.

\section{Acknowledgements}

This work has been funded by the Department of Chemical Engineering and Polymer Science, Shahjalal University of Science and Technology, Bangladesh. We are thankful to Universiti Malaysia Pahang for collaboration in this project.

\section{References}

[1] Castro E, Avellaneda A, Marco P. Combination of advanced oxidation processes and biological treatment for the removal of benzidine-derived dyes. Environmental Progress \& Sustainable Energy. 2014; 33(3): 873-885.

[2] Jassal V, Shanker U, Kaith BS, et al. Green synthesis of potassium zinc hexacyanoferrate nanocubes and their potential application in photocatalytic degradation of organic dyes. RSC Advances. 2015; 5: 26141-26149.

[3] Khan MMR, Mukhlish MZB, Mazumder MSI, et al. Uptake of Indosol Dark-blue GL dye from aqueous solution by water hyacinth roots powder: adsorption and desorption study. International Journal of Environmental Science and Technology. 2014; 11: 1027-1034.

[4] Noroozi B, Sorial GA, Bahrami H, et al. Equilibrium and kinetic adsorption study of a cationic dye by a natural adsorbent-silkworm pupa. Journal of Hazardous Materials. 2007; 139: 167-174.

[5] Mukhlish MZB, Khan MR., Bhoumick MC, et al. Leaf powder: novel adsorbent for removal of Methylene blue from aqueous solution. Water, Air, \& Soil Pollution. 2012; 223: 4949-4958.

[6] Riera-Torres M, Gutiérrez-Bouzán C, Crespi M. Combination of coagulation flocculation and nanofiltration techniques for dye removal and water reuse in textile effluents. Desalination. 2010; 252(1-3): 53-59.

[7] Salmani ER, Ghorbanian A, Ahmadzadeh S, et al. Removal of Reactive Red 141 Dye from synthetic wastewater by electrocoagulation process: investigation of operational parameters. Iranian Journal of Health, Safety \& Environment. 2016; 3(1): 403-411.

[8] Alver E, Metin AÜ. Anionic dye removal from aqueous solutions using modified zeolite: Adsorption kinetics and isotherm studies. Chemical Engineering Journal. 2012; 200-202: 59-67.

[9] Kansal S, Kaur N, Singh S. Photocatalytic degradation of two commercial reactive dyes in aqueous phase using nanophotocatalysts. Nanoscale Research Letters. 2009; 4(7): 709-716.

[10] Gowri RS, Vijayaraghavan R, Meenambigai, P. Microbial degradation of reactive dyes- A Review. International Journal of Current Microbiology and Applied Sciences. 2014; 3(3): 421-436.

[11] Fettouche S, Tahiri M, Madhouni R, et al. Removal of reactive dyes from aqueous solution by adsorption onto Alfa fibers powder. Journal of Materials and Environmental Science. 2015; 6(1): 129-137. 
[12] Geethakarthi A, Phanikumar BR. Adsorption of reactive dyes from aqueous solutions by tannery sludge developed activated carbon: kinetic and equilibrium studies. International Journal of Environmental Science and Technology. 2011; 8(3): 561-570.

[13] Manoukian M, Fashandi H, Tavakol H. Polysulfone-highly uniform activated carbon sphere mixed-matrix membrane intended for efficient purification of dye wastewater. Materials Research Express. 2019; 6(5): 055313. Available from: https://doi.org/10.1088/2053-1591/ab03fa.

[14] Zafar MS, Tausif M, Mohsin M, et al. Potato starch as a coagulant for dye removal from textile wastewater. Water, Air, \& Soil Pollution. 2015; 226: 1-11.

[15] Amuda OS, Amoo IA. Coagulation/flocculation process and sludge conditioning in beverage industrial wastewater treatment. Journal of Hazardous Materials. 2007; 141(3): 778-783.

[16] Gao BY, Yue QY, Wang Y, et al. Color removal from dye-containing wastewater by magnesium chloride. Journal of Environmental Management. 2007; 82: 167-172.

[17] Lacasse K, Baumann W. Textile Chemicals: Environmental Data and Facts. Springer-verlag Berlin Heidelberg; 2004. Available from: DOI: 10.1007/978-3-642-18898-5.

[18] Shahbazi D, Mousavi SA, Nayeri D. Low-cost activated carbon: characterization, decolorization, modeling, optimization and kinetics. International Journal of Environmental Science and Technology. 2020. Available from: https://doi.org/10.1007/s13762-020-02698-w.

[19] Bakhshi P, Tavakol H. Oil removal from water using highly hydrophobic, ultralight carbon microspheres. International Journal of Environmental Science and Technology. 2020; 17: 1649-1656.

[20] Manoukian M, Tavakol H, Fashandi H. Synthesis of highly uniform sulfur-doped carbon sphere using CVD method and its application for cationic dye removal in comparison with undoped product. Journal of Environmental Chemical Engineering. 2018; 6(6): 6904-6915.

[21] Ghorbani F, Kamari S. Core-shell magnetic nanocomposite of Fe3O4@SiO2@NH2 as an efficient and highly recyclable adsorbent of methyl red dye from aqueous environments. Environmental Technology \& Innovation. 2019; 14(100333): 1-16. Available from: https://doi.org/10.1016/j.eti.2019.100333.

[22] Mashkoor F, Nasar A, Inamuddin, et al. Exploring the reusability of synthetically contaminated wastewater containing crystal violet dye using Tectona grandis sawdust as a very low-cost adsorbent. Scientific Reports. 2018; 8(8314): 1-16. Available from: https://doi.org/10.1038/s41598-018-26655-3.

[23] Georgin J, Marques BS, Peres EC, et al. Biosorption of cationic dyes by Pará chestnut husk (Bertholletia excelsa). Water Science \& Technology. 2018; 77: 1612-1621.

[24] Humelnicu I, Băiceanu A, Ignat M-E, et al. The removal of Basic Blue 41 textile dye from aqueous solution by adsorption onto natural zeolitic tuff: kinetics and thermodynamics. Process Safety and Environmental Protection. 2017; 105: 274-287.

[25] Abukhadra MR, Shaban M. Recycling of different solid wastes in synthesis of high-order mesoporous silica as adsorbent for safranin dye. International Journal of Environmental Science and Technology. 2019; 16: 7573-7582.

[26] Ayazi Z, Khoshhesab ZM, Azhar FF, et al. Modeling and optimization of adsorption removal of Reactive Orange 13 on the alginate-montmorillonite-polyaniline nanocomposite via response surface methodology. Journal of the Chinese Chemical Society. 2017; 64: 627-639.

[27] Crini G, Lichtfouse E. Advantages and disadvantages of techniques used for wastewater treatment. Environmental Chemistry Letters. 2019; 17(1): 145-155.

[28] Jiuhui QU. Research progress of novel adsorption processes in water purification: A review. Journal of Environmental Sciences. 2008; 20(1): 1-13.

[29] Shi C, Lv C, Wu L, et al. Porous chitosan/hydroxyapatite composite membrane for dyes static and dynamic removal from aqueous solution. Journal of Hazardous Materials. 2017; 338: 241-249.

[30] Zhan Y, Wan X, He S, et al. Design of durable and efficient poly (arylene ether nitrile)/bioinspired polydopamine coated graphene oxide nanofibrous composite membrane for anionic dyes separation. Chemical Engineering Journal. 2018; 333: 132-145.

[31] Karim Z, Mathew AP, Grahn M, et al. Nanoporous membranes with cellulose nanocrystals as functional entity in chitosan: removal of dyes from water. Carbohydrate polymers. 2014; 112: 668-676.

[32] Peydayesh M, Mohammadi T, Bakhtiari O. Effective treatment of dye wastewater via positively charged TETAMWCNT/PES hybrid nanofiltration membranes. Separation and Purification Technology. 2018; 194: 488-502.

[33] Puchana-Rosero MJ, Lima EC, Mella B, Costa DD, et al. A coagulation-flocculation process combined with adsorption using activated carbon obtained from sludge for dye removal from tannery wastewater. Journal of the Chilean Chemical Society. 2018; 63(1): 3867-3874.

[34] Teh CY, Budiman PM, Shak KPY, et al. Recent advancement of coagulation-flocculation and its application in wastewater treatment. Industrial \& Engineering Chemistry Research. 2016; 55(16): 4363-4389. 
[35] Rossini M, Garrido J, Galluzzo M. Optimization of the coagulation-flocculation treatment: influence of rapid mix parameters. Water Research. 1999; 33(8): 1817-1826.

[36] Yonar T. Decolorisation of textile dyeing effluents using advanced oxidation processes. In: Prof. Peter Hauser (Ed.) Advances in Treating Textile Effluent. Croatia: IntechOpen; 2011. P. 1-26. Available from: DOI: 10.5772/18908.

[37] Katheresan V, Kansedo J, Lau SY. Efficiency of various recent wastewater dye removal methods: A review. Journal of Environmental Chemical Engineering. 2018; 6: 4676-4697.

[38] Kim T-H, Park C, Yang J, et al. Comparison of disperse and reactive dye removals by chemical coagulation and Fenton oxidation. Journal of Hazardous Materials. 2004; B112: 95-103.

[39] Kuo WG. Decolorizing dye wastewater with Fenton's reagent. Water Research. 1992; 26(7): 881-886.

[40] Yonar,T, Kestioglu K, Azbar N. Treatability studies on domestic wastewater using UV/H2O2 process. Applied Catalysis B: Environmental. 2006; 67(3-4): 223-228.

[41] Friha I, Bradai M, Johnson D, et al. Treatment of textile wastewater by submerged membrane bioreactor: in vitro bioassays for the assessment of stress response elicited by raw and reclaimed wastewater. Journal of Environmental Management. 2015; 160: 184-192.

[42] Zahraa SH, Gzar HA. Evaluation of the performance of MBR-RO technology for treatment of textile wastewater and reuse. In: IOP 2019: Conference on Civil and Environmental Engineering Technologies: IOP Conference Series: Materials Science and Engineering. IOP publishing. 2019; 584(012049). P.1-9. Available from: doi:10.1088/1757$899 X / 584 / 1 / 012049$.

[43] Castañeda-Díaz J, Pavón-Silva T, Gutiérrez-Segura E, et al. Electrocoagulation-adsorption to remove anionic and cationic dyes from aqueous solution by PV-energy. Journal of Chemistry. 2017; 2017(5184590): 1-14. Available from: https://doi.org/10.1155/2017/5184590.

[44] Song S, He Z, Qiu J, et al. Ozone assisted electrocoagulation for decolorization of C.I. Reactive Black 5 in aqueous solution: an investigation of the effect of operational parameters. Separation and Purification Technology. 2007; 55(2): 238-245.

[45] Gogate PR, Bhosale GS. Comparison of effectiveness of acoustic and hydrodynamic cavitation in combined treatment schemes for degradation of dye wastewaters. Chemical Engineering and Processing: Process Intensification. 2013; 71: 59-69.

[46] Xu L, Du LS, Wang C, et al. Nanofiltration coupled with electrolytic oxidation in treating simulated dye wastewater. Journal of Membrane Science. 2012; 409-410: 329-334.

[47] Gümüşdere HT, Artan T, Güvenç A, et al. Textile azo dyes decolourization by combined ultrasonication and microbial removal. In: H. Gökçekus, U. Türker \& W. J. LaMoreaux (Eds.) Survival and Sustainability: Environmental concerns in the 21st Century. Berlin: Heidelberg: Springer Berlin Heidelberg. 2011; 885-892.

[48] Merzouk B, Gourich B, Madani K, et al. Removal of a disperse red dye from synthetic wastewater by chemical coagulation and continuous electrocoagulation. A comparative study. Desalination. 2011; 272(1-3): 246-53.

[49] Mukhlish MZB., Khan MMR., Islam AR, et al. Removal of reactive dye from aqueous solution using coagulationflocculation coupled with adsorption on papaya leaf. Journal of Mechanical Engineering and Sciences. 2016; 10(1): 1884-1894.

[50] Ahn D, Chang W, Yoon T. Dyestuff wastewater treatment using chemical oxidation, physical adsorption and fixed bed biofilm process. Process Biochemistry. 1999; 34(5): 429-439.

[51] Amin MT, Alazba AA, Shafiq M. Adsorptive Removal of Reactive Black 5 from Wastewater Using Bentonite Clay: Isotherms, Kinetics and Thermodynamics. Sustainability. 2015; 7: 15302-15318.

[52] Nia RH, Ghaedi M, Ghaedi AM. Modeling of reactive orange 12 (RO 12) adsorption onto gold nanoparticle-activated carbon using artificial neural network optimization based on an imperialist competitive algorithm. Journal of Molecular Liquids. 2014; 195: 219-229.

[53] Koohestanian A, Hosseini M, Abbasian Z. The separation method for removing of colloidal particles from raw water, American-Eurasian. Journal of Agricultural \& Environmental Sciences. 2008; 4(2): 266-273.

[54] Daud Z, Awang H, Latif AAA, et al. Suspended solid, color, COD and oil and grease removal from biodiesel wastewater by coagulation and flocculation processes. Procedia-Social and Behavioral Sciences. 2015; 195: 24072411.

[55] Duan J, Gregory J. Coagulation by hydrolyzing metal salts. Advances in Colloid and Interface Science. 2003; 100102: 475-502.

[56] Selcuk H. Decolorization and detoxification of textile wastewater by ozonation and coagulation processes. Dyes and Pigments. 2005; 64: 217-222.

[57] Chiang P-C, Chang E-E, Chang P-C, et al. Effects of pre-ozonation on the removal of THM precursors by coagulation. Science of the Total Environment. 2009; 407(21): 5735-5742.

[58] Wong PW, Teng TT, Norulaini NARN. Efficiency of the coagulation-flocculation method for the treatment of dye 
mixtures containing disperse and reactive dye. Water Quality Research Journal of Canada. 2007; 42(1): 54-62.

[59] Mohamed RMSR, Nanyan N, Rahman MNFA, et al. Colour removal of reactive dye from textile industrial wastewater using different types of coagulants. Asian Journal of Applied Sciences. 2014; 2(5): 650-657.

[60] Azbar N, Yonar T, Kestioglu K. Comparison of various advanced oxidation processes and chemical treatment methods for COD and colour removal from a polyester and acetate fiber dyeing effluent. Chemosphere. 2004; 55: 35-43.

[61] Nidheesh P, Zhou M, Oturan MA. An overview on the removal of synthetic dyes from water by electrochemical advanced oxidation processes. Chemosphere. 2018; 197: 210-227.

[62] Aziz ARA, Asaithambi P, Daud WMABW. Combination of electrocoagulation with advanced oxidation processes for the treatment of distillery industrial effluent. Process Safety and Environmental Protection. 2016; 99: $227-235$.

[63] Haji S, Benstaali B, Al-Bastaki N. Degradation of methyl orange by $\mathrm{UV} / \mathrm{H}_{2} \mathrm{O}_{2}$ advanced oxidation process. Chemical Engineering Journal. 2011; 168: 134-139.

[64] Buxton GV, Greenstock CL, Helman WP, et al. Critical Review of rate constants for reactions of hydrated electrons, hydrogen atoms and hydroxyl radicals in aqueous solution. Journal of Physical and Chemical Reference Data. 1988; 17: 513-886.

[65] Galindo C, Kalt A. UV- $\mathrm{H}_{2} \mathrm{O}_{2}$ oxidation of monoazo dyes in aqueous media: a kinetic study. Dyes and Pigments. 1998; 40: $27-35$.

[66] Islam MS, Kusumoto Y, Abdulla-Al-Mamun M, et al. Enhancement of cumulative photoirradiated and AC magneticfield induced cancer (HeLa) cell killing efficacy of mixed $\alpha$ and $\gamma-\mathrm{Fe}_{2} \mathrm{O}_{3}$ magnetic nanoparticles. New Journal of Chemistry. 2012; 36: 1201-1209.

[67] Saien J, Soleymani AR. Feasibility of using a slurry falling film photo-reactor for individual and hybridized AOPs. Journal of Industrial and Engineering Chemistry. 2012; 18(5): 1683-1688.

[68] Mousavi SA, Sohrabi P, Mohammadi P, et al. Investigation of the efficiency of UV/H2O2 process on the removal of Rhodamine B from aqueous solutions. International Research Journal of Applied and Basic Sciences. 2016; 10(5): 456-459.

[69] Furlan FR, de Melo da Silva LG, Morgado AF, et al. Removal of reactive dyes from aqueous solutions using combined coagulation/flocculation and adsorption on activated carbon. Resources, Conservation and Recycling. 2010; 54(5): 283-290.

[70] Harrelkas F, Azizi A, Yaacoubi A, et al. Treatment of textile dye effluents using coagulation-flocculation coupled with membrane processes or adsorption on powdered activated carbon. Desalination. 2009; 235: 330-339. 